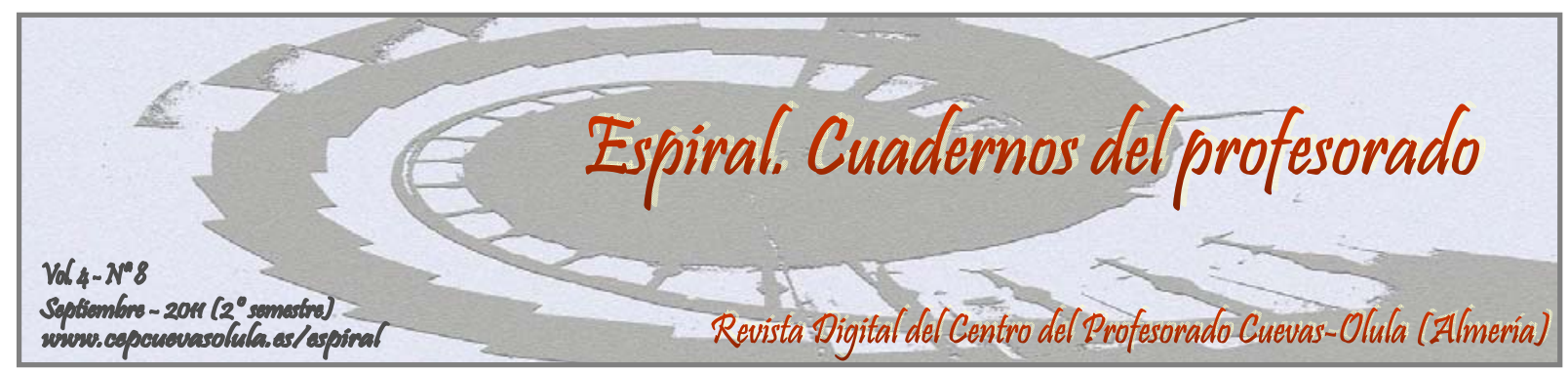

\title{
LA IGUALDAD DE OPORTUNIDADES ENTRE AMBOS SEXOS: TÉCNICAS PARA LOGRAR UN RETO
}

\section{EQUAL OPPORTUNITIES FOR BOTH SEXES: TECHNIQUES TO ACHIEVE A CHALLENGUE}

\author{
Lidia Irene Olmos Moreno
}

IES Juan Rubio Ortiz de Macael, Almería

\begin{abstract}
RESUMEN: La experiencia que se presenta muestra algunas de las tareas y materiales que han sido empleados con alumnado de secundaria para trabajar el tema transversal de la igualdad de oportunidades entre ambos sexos. El objetivo de este trabajo es ofrecer al docente herramientas, estrategias, material e ideas para que aborde en el aula la problemática de la desigualdad existente entre hombres y mujeres, teniendo como meta el logro, en nuestro alumnado, de actitudes y comportamientos basados en la igualdad y el respeto entre personas de ambos sexos. Se ha utilizado una metodología ecléctica, donde se combinan momentos de indagación e investigación, individual y en grupo, haciendo uso de las nuevas tecnologías, con otros de reflexión acerca de los nuevos conocimientos adquiridos, para llegar así a lo que más nos interesa: el propio alumnado extrae conclusiones que lo hacen capaz de detectar y corregir comportamientos machistas presentes en su propio entorno. El resultado de trabajar este tema con el alumnado es muy positivo ya que con actividades como las que se proponen, logramos que los jóvenes introduzcan cambios en su propio comportamiento, que, inconscientemente, entraña diversos tipos de discriminación hacia la mujer. La escuela es uno de los principales escenarios desde donde deben corregirse situaciones y comportamientos machistas.
\end{abstract}

Palabras clave: igualdad, educación en valores, discriminación, machismo, antropocentrismo.

ABSTRACT: This paper shows some of the tasks and materials that have been used with secondary school students to work on the cross-cutting theme of equal opportunities between the sexes. The aim of this paper is to provide teaching tools, strategies, materials and ideas for the classroom that address the problem of inequality between men and women, with the goal of achieving in our students, attitudes and behaviors based on equality and respect between people of both sexes. A varied/eclectic methodology has been used, combining moments thinking, investigating, individually and in group, using new technologies, with moments reflecting about new acquired knowledge, taking us to the most important thing: the pupil himself makes conclusions which let him see and correct sexist behaviour which exists in his environment. The result of dealing with this topic with the students is very positive because the activities proposed make possible for teenagers to introduce changes in their behaviour which, unconsciously, creates several kinds of discrimination towards women. School is one very important scenery where sexist situations and behaviour must be corrected.

Key words: equality, values education, discrimination, sexism, anthropocentrism. 
Olmos Moreno, L.I. (2011). La igualdad de oportunidades entre ambos sexos: técnicas para lograr un reto. Espiral. Cuadernos del Profesorado, 4(8), 58-68. Disponible en: http://www.cepcuevasolula.es/espiral.

Fecha de recepción: 07/06/2011

Fecha de aceptación: 21/08/2011
Enviar correspondencia a: nereida-25@hotmail.com

\section{1.- INTRODUCCIÓN}

En los últimos años, se han llevado a cabo estudios sobre el modelo educativo existente que han detectado ámbitos del proceso educativo y de sus resultados en los que se pone de manifiesto que, hoy por hoy en la escuela, todavía perduran elementos que reproducen y perpetúan el sexismo y las diferencias entre los futuros hombres y mujeres que formarán nuestra sociedad. (Red2Red, 2007).

La Ley Orgánica de Educación (LOE) recoge como uno de los temas trasversales que, por tanto, debe abordarse en todas las materias, la igualdad de oportunidades para ambos sexos. No en vano, se ha venido imponiendo el concepto de "coeducación”, para referirse a esa búsqueda de una educación basada en la igualdad y cuyo fin último es erradicar los estereotipos entre sexos, superando las desigualdades sociales y las jerarquías culturales entre niños y niñas. Son numerosos los materiales didácticos, orientados a este fin, con los que contamos en la actualidad, tanto elaborados y editados por las Consejerías de Educación así como por organismos, particulares, asociaciones, etc. Así mismo, cada vez proliferan más eventos orientados a lograr comportamientos basados en la igualdad entre nuestro alumnado, como por ejemplo el Concurso sobre igualdad de género de la Fundación José Tomás, celebrado, por primera vez, durante este curso (2010/2011).

El tema de la igualdad de oportunidades entre hombres y mujeres abarca un gran abanico de posibilidades a la hora de tratarlo en clase: se puede estudiar el origen del machismo desde culturas ancestrales (Harris, 1983), el trato desigual que ha recibido la mujer a lo largo de la historia (Aznar y Cánovas, 2008), los roles que ha venido desempeñando en la sociedad, sus actuaciones (y discriminaciones) en el mundo laboral (Subirats, 1993), la situación actual con el problema latente de la violencia de género y un largo etcétera. Como ocurre siempre que se nos acota tan poco una tarea o tema que ha de tratarse en el aula, el principal dilema es concretar qué actuaciones deben llevarse a cabo, qué enfoque es el más apropiado, qué herramientas utilizar y, en definitiva, qué estrategias emplear para lograr dicho objetivo: promover la igualdad entre hombres y mujeres.

En la materia optativa Cambios sociales y nuevas relaciones de género que se imparte en Educación Secundaria Obligatoria (ESO), se trata este tema con detenimiento y se accede a un gran abanico de posibilidades y experiencias por poder contar con dos horas semanales.

$\mathrm{Al}$ margen de dicha materia que se pone, por entero, al servicio de este tema transversal (La igualdad de oportunidades entre ambos sexos), lo cierto es que deben promoverse situaciones, tareas, experiencias con el alumnado para lograr este fin y cuando no se tiene todo el tiempo que se consideraría necesario porque priman los contenidos curriculares y competencias, se hace obligatorio buscar maneras alternativas de lograr dicho propósito sin menoscabo de la programación docente.

La experiencia que aquí se presenta puede llevarse a la práctica de forma total o parcial, dependiendo del tiempo del que se disponga, de la materia desde la que se parta, los grupos a los que se dirija, etc.

La finalidad de compartir esta experiencia no es otra que la de ofrecer estrategias, tareas, ideas a otros docentes que quieran trabajar este tema que, por ser tan amplio, hace que, frecuentemente, no sepamos de dónde partir ni cómo abordarlo de forma efectiva. Presentamos instrumentos que acercan al alumnado a situaciones de discriminación que se producen, de forma habitual, en su propio entorno, para que tome conciencia de ellas y pueda erradicarlas o corregirlas (Lobato, 2010). 


\section{2.- ORIGEN DE LA EXPERIENCIA}

La experiencia que aquí se propone se desarrolló en el contexto de la materia de Cambios sociales y nuevas relaciones de género ( $2^{\circ}$ de ESO) en un IES de la provincia de Granada (IES Benalúa). Se buscaba, al mismo tiempo, promover experiencias y tareas que favorecieran la mejora de la competencia lingüística y, concretamente, la expresión y comprensión escritas. Por este motivo, en la mayoría de los casos, el alumnado tenía que leer textos, reflexionar sobre ellos, y crear otros nuevos, tanto de forma oral como escrita.

La materia en la que se enmarca esta experiencia (Cambios sociales y nuevas relaciones de género) cuenta con dos horas semanales, con lo cual, no es posible presentar aquí todas las tareas llevadas a cabo durante todo el curso. Por este motivo, se hablará sólo de aquellas que se encuentran entre las que resultaron más motivadoras, más interesantes, dinámicas o fructíferas. Son numerosas las tareas que se realizaron, todas ellas con el objetivo común de lograr la igualdad entre hombres y mujeres.

Aunque puede encontrarse material didáctico para trabajar en esta materia (puede utilizarse como punto de partida, muy positivamente, la Guía didáctica Cambios Sociales y de género, editada por la Junta de Andalucía), se elaboraron tareas y materiales propios, originales, porque se partía de la premisa de que el reto no era otro que conseguir que el alumnado se diera cuenta de que, en su propio entorno, existían tratos desiguales hacia la mujer y que pasan inadvertidos ante sus ojos, tratos que ellos mismos podían corregir. Se elaboró material nuevo para lograr el reto marcado desde el principio: que el alumnado conectara los nuevos aprendizajes con su propia experiencia.

El grupo de alumnos y alumnas al que se dirigieron estas tareas era bastante homogéneo. Contaba con cinco chicos y siete chicas de entre 12 y 14 años. La mayoría eran de etnia gitana, donde el machismo se hereda (Moreno y Sánchez-Oro, 2000) y, lo que es peor, la mujer gitana lo asume y reproduce sin someterlo a crítica. Esta situación de partida ya suponía un nuevo reto, pues si es difícil analizar situaciones de machismo presentes en el entorno y que el alumnado (sobre todo, los varones) lo reconozca, más difícil sería lograr que chicos gitanos asumieran que había machismo en muchos de sus comportamientos y, yendo aún más allá, que los corrigieran. Evidentemente, con las tareas llevadas a cabo, no se consiguió erradicar dichos comportamientos pero, al menos, sí se pudo lograr que el alumnado reflexionara sobre ellos, los extrapolara al terreno personal y, en muchos casos, reconociera que sufría esa discriminación (las chicas) o que actuaba de forma machista (chicos y, curiosamente, chicas en algunos casos).

Otro aspecto positivo que se puede destacar es que en muchas tareas se implicaba a las familias (encuestas que debía pasarle el alumnado, entrevistas, etc.) con lo que se lograba, en mayor o menor medida que, al menos, se cuestionaran muchas de las situaciones y comportamientos por los que les preguntaban sus hijos.

\section{3.- OBJETIVOS}

Con las actividades realizadas y que se presentan más adelante se pretende dar respuestas a los siguientes objetivos:

1. Combatir la discriminación hacia la mujer.

2. Reflexionar y erradicar los estereotipos sexistas.

3. Acabar con las jerarquías por motivos de género.

4. Diferenciar los conceptos de sexo y género.

5. Conocer someramente datos históricos que muestran que la mujer siempre ha estado en un segundo plano con respecto al hombre.

6. Detectar comportamientos machistas en el entorno propio: cuentos infantiles, publicidad, hogar, profesiones, etc.

7. Corregir comportamientos machistas o de discriminación hacia la mujer. 


\section{4.- METODOLOGÍA}

Teniendo en cuenta que en Enseñanza Secundaria Obligatoria (ESO) debemos conseguir que nuestro alumnado desarrolle, entre otras, la competencia de aprender a aprender y la de la autonomía e iniciativa personal, no cabe contemplar otra metodología que no sea la que entienda al alumno como eje y motor del proceso de enseñanza/aprendizaje. El profesor, únicamente, debe facilitar al alumnado las herramientas necesarias para que llegue al fin propuesto. Así pues, se fomentará, siempre que sea posible, la actitud indagadora y analítica en el alumnado. Esta ha de ser la tónica común en la mayoría de las tareas pues, de esta forma, el alumnado aprende realmente, se implica en su propio aprendizaje, porque adopta un papel eminentemente activo en él (Estaire, 2004).

La metodología empleada en las tareas que se presentan es muy práctica e intuitiva. Primero se presentaba el tema sobre el que se iba a trabajar (la mujer en la publicidad, la mujer en las religiones, el machismo en la literatura infantil, la mujer en el mundo laboral, etc.). Se daba información sobre dicho tema, datos concretos extraídos de estudios, informes, noticias, etc. Después se presentaba la tarea, para cuya realización tendrían que trabajar, normalmente, en pareja o pequeño grupo (siguiendo a Pujolás (2001), el aprendizaje colaborativo es muy enriquecedor). Realizada la tarea, se producía un debate en gran grupo sobre el tema trabajado, la información nueva a la que habían accedido, los resultados obtenidos tras realizar la tarea y sus opiniones o percepciones acerca de la problemática analizada, intentando siempre conectar con situaciones relacionadas con su propia experiencia, su entorno.

Para la mayoría de tareas, el alumnado debía consultar fuentes de información digitales (se le facilitaban las páginas Web de las que se había extraído la información, en otras ocasiones tenían que documentarse de forma autónoma para realizar la tarea). También se trabajó continuamente con la prensa (en papel y digital), y, en cada tarea, el alumnado tenía que expresarse oralmente (en los debates) y por escrito (recogida de conclusiones, opiniones, descripción de situaciones cotidianas que presentaban algún tipo de discriminación, reescritura de cuentos desde una perspectiva no machista, etc.).

Es evidente, por tanto, que se ha trabajado enormemente la comprensión y expresión escritas, buscando mejorarlas, así como incrementar el caudal léxico (era constante el uso del diccionario para la elaboración de un glosario propio al que se llamó "glosario coeducativo", y que recogía palabras nuevas relacionadas con esta temática: patriarcado, sexismo, feminismo, androcentrismo, etc.), la velocidad lectora, la capacidad de discriminar información principal y secundaria, sintetizar y resumir $\mathrm{y}$, en última instancia, se ha promovido, en mayor o menor medida, una actitud crítica ante la información que presentaban aquellos textos que leían.

\section{5.- TAREAS LLEVADAS A CABO PARA REFLEXIONAR SOBRE SITUACIONES DE DISCRIMINACIÓN HACIA LA MUJER.}

\section{Tarea 1: Análisis de la mujer en la publicidad}

Es muy raro que aparezcan en publicidad mujeres realizando profesiones consideradas tradicionalmente para hombres y los medios refuerzan esta labor, ya que en las series no se ha visto una mujer bombero, una mujer conductora de taxis o de autobuses, o los programas de cocina no están llevados por mujeres, sino que los grandes chefs son hombres. Ellas tienen que ver con la responsabilidad, las obligaciones y los valores (Suárez Villegas, 2007).

En la publicidad y los medios de comunicación, las mujeres suelen ser tiernas, afectivas, débiles, solícitas, intuitivas, temerosas, coquetas. Además, se abusa de la exhibición del cuerpo femenino (son muchos los anuncios publicitarios en los que, sin necesidad aparente, se muestra el cuerpo desnudo de la mujer).

Sin embargo, los hombres suelen presentarse como valientes, activos, inteligentes, tenaces, seguros.

Suárez Villegas recoge en su artículo algunos estereotipos (o roles) que la mujer representa en los anuncios publicitarios: 
a) La abuelita previsora: mujer que ofrece la seguridad de la experiencia, representa la tranquilidad, la importancia de la familia y de la tradición. Suele presentarse como una mujer que viste bien, que no presenta achaques, que se cuida, y que disfruta con sus nietos o preparando una comida en familia.

b) El ama de casa: en anuncios que promocionan comida y productos de limpieza, aparece la mujer. Son muy pocos los anuncios de este tipo protagonizados por hombres (sólo en los que se pretende transmitir que lo que se anuncia es fácil de hacer o de utilizar). El ama de casa que se muestra es una mujer atractiva, feliz, coqueta, que busca agradar a su marido y sus hijos.

c) La triunfadora profesional: hermosa, viste con elegancia y buen gusto, es admirada por sus compañeros masculinos.

d) La mujer objeto: en este caso, la mujer no tiene identidad, personalidad; es un reclamo sexual, un objeto susceptible de ser adquirido por el hombre. (Este tipo de anuncios es muy criticado por los colectivos feministas).

Analizada esta situación, la tarea que formulamos a nuestro alumnado es la siguiente: observa la televisión, revistas, periódicos o Internet y selecciona anuncios publicitarios que reflejen estos estereotipos.

En todos los casos, era muy sencillo encontrar anuncios en los que aparecía el ama de casa, promocionando productos de limpieza, comida, electrodomésticos. Los anuncios de comida protagonizados por hombres siempre correspondían a comida precocinada o cuya elaboración es sumamente sencilla. ¿Por qué? Llegamos a la conclusión de que, con este tipo de anuncios se perpetúa la creencia de que el hombre no sabe ni quiere cocinar y que, por ese motivo, recurre a este tipo de comida de fácil preparación mientras que la mujer sí disfruta en la cocina preparando platos elaborados.

A los alumnos/as les costó trabajo hallar anuncios en los que apareciera la triunfadora profesional (alguno que promocionaba un complemento vitamínico para aguantar el ritmo de una mujer que trabaja dentro y fuera de casa; otro de una pomada para aliviar las piernas cansadas y alguno de comida envasada, susceptible de ser llevada al trabajo). No fue difícil encontrar aquéllos protagonizados por elegantes hombres de negocios que promocionaban coches, trajes, relojes, perfumes...

El estereotipo más abundante era el de la mujer objeto: para anunciar perfumes, bombones, helados, algún coche, productos para el pelo... haciendo hincapié en mostrar la belleza del cuerpo femenino y sugiriendo que el resto de las mujeres necesitan el producto anunciado para lograr la belleza de la mujer que se presenta.

Después de analizar los numerosos anuncios publicitarios, todo el alumnado coincidía en que hay sexismo en muchos de ellos y que así se refuerzan los roles que ha venido desempeñando el hombre y la mujer en la sociedad: mujer ama de casa (pero feliz) y mujer como objeto sexual por un lado; hombre inteligente, valiente, elegante y triunfador, sin tiempo para los quehaceres del hogar, por otro.

A partir de esta conclusión, los alumnos reflexionaron sobre dichos roles, coincidiendo en la mayoría de los casos en la opinión de que dichos anuncios reflejaban la realidad, puesto que, según su propia experiencia, eran sus madres, abuelas, tías las que iban a la compra, cocinaban, limpiaban y cuidaban de los niños pequeños mientras que los padres, abuelos y tíos eran los que trabajaban fuera, tenían el coche, y pasaban poco tiempo en casa (con lo cual, ni cocinaban ni limpiaban). En la mayoría de los casos, el alumnado reconoce que se trata de una situación de discriminación hacia la mujer, que no ha tenido las mismas oportunidades que el hombre para abrirse camino en el mundo laboral o que, en muchos casos, ha pesado más la tradición que las aspiraciones profesionales (recordemos que mi alumnado era, en su mayoría, de etnia gitana, donde el papel de la mujer-ama de casa/madre/esposa, es el que impera por encima de la mujer-trabajadora/culta/independiente/triunfadora profesionalmente).

Formamos tres grupos de alumnos y alumnas y cada uno realizó un anuncio publicitario que fuera en contra del sexismo detectado en publicidad: un chico anunció un detergente, una chica un 
coche y, por último, un chico promocionó una crema de protección solar (hay que decir que, en un principio, este último anuncio era de una crema antiarrugas pero el alumno no conseguía actuar de forma natural y seria, con lo que pidió que en lugar de promocionar dicha crema, anunciaría una crema solar. Con ello vemos los prejuicios que, después de analizarlos y reflexionar sobre ellos, siguen teniendo nuestros jóvenes).

\section{Tarea 2: Machismo en distintas religiones}

En el imperio Griego, famoso por sus amplias tradiciones y mitos religiosos posteriormente heredados por los Romanos, podemos encontrar una buena cantidad de diosas, cuyas cualidades están muy relacionadas con características desde entonces consideradas como femeninas, como la castidad (Artemisa), la belleza y el amor (Afrodita), la fecundidad (Démeter), e incluso las virtudes domésticas (Hestia). Otras deidades y creaciones mitológicas greco-romanas poseen rasgos negativos como venganza (Némesis), castigo (Furias o Erinias), sexualidad insaciable (Ninfas), protectoras del infierno (Parcas), y las famosas monstruos que convertían en piedra a quienes las miraban (Gorgonas, tres hermanas entre las que se encontraba Medusa). En estos imperios, la mujer era considerada inferior al hombre, por lo que no ocupaba ningún cargo religioso, de hecho, algunos historiadores dicen que sólo salían de sus hogares para traer agua o visitar a otra mujer, y estaban sometidas a su padre y posteriormente a su marido. Muchos antropólogos defienden que es el Imperio GrecoRomano, el de mayor duración y extensión a través de la historia, el que se encarga de propagar la discriminación a la mujer, ya desde el mito de Pandora.

El hinduismo defiende que la mujer debe mantenerse permanentemente dependiente del hombre: durante su infancia, una mujer tiene que depender de su padre; durante su juventud, de su marido; si ha muerto su marido, de sus hijos; si no tiene hijos, de los parientes próximos de su marido y, en su defecto, de los de su padre; si no tiene parientes paternos, del soberano: una mujer no debe nunca gobernarse a su antojo.

Otra religión ampliamente extendida en Oriente es el Islam, que comparte junto con el Judaísmo y la Cristiandad la esencia de un mismo Dios, ya se le llame Yahvé, Jehová, o Allah. El Islam ha sido ampliamente criticado por su discriminación hacia las mujeres, por exigirles prácticas como la de portar el velo o Hijab, que ellas mismas justifican alegando obediencia a un Dios supremo y sus sagradas reglas, mostradas en uno de los pasajes del Corán: " $Y$ diles a las mujeres creyentes que bajen su mirada y que protejan sus partes privadas (de actos sexuales ilícitos) y que no muestren su belleza más que lo que tiene que verse, y que sus velos cubran su rostro". (Corán 24:31).

En las religiones de la Cristiandad la balanza del poder se inclina sobremanera hacia los hombres en la Biblia, induciéndolos incluso, a la discriminación hacia la mujer. Ténganse en cuenta los siguientes pasajes: "A la mujer dijo (Dios): Aumentaré en gran manera el dolor de tu preñez; con dolores de parto darás a luz hijos, y tu deseo vehemente será por tu esposo, y él te dominará". (Génesis 3:16) (EVA). "Como en todas las congregaciones de los santos, las mujeres guarden silencio porque no se permite que hablen, sino que estén en sujeción, tal como dice la Ley. Pues, si quieren aprender algo, interroguen a sus propios esposos en casa, porque es vergonzoso que una mujer hable en la congregación.” (1 Corintios 14:33-35)

Aunque el pensamiento ha ido evolucionando, no lo ha hecho de forma suficiente como para dar la misma igualdad de derechos a ambos géneros, y ello puede ser notado en casi todas las hermandades cristianas existentes alrededor del mundo. Así, por ejemplo, los cargos eclesiásticos importantes (Papa, obispos, cardenales, etc.) son ocupados única y exclusivamente por hombres, de hecho, son estos los únicos que tienen permitido oficiar una misa.

Después de reflexionar con el alumnado sobre esta información (los diferentes libros sagrados obligan a la mujer a ser sumisa y vivir subyugada al hombre), la tarea que debían realizar era la siguiente: busca en Internet la historia de Pandora y la de Eva y compara el papel de ambas en cada religión.

Ninguno de los alumnos/as conocía la historia de Pandora. Acceder a ella les permitió darse cuenta de que tanto Pandora en la religión mitológica clásica como Eva en el cristianismo, son 
dibujadas como las culpables de los males del mundo; ambas se dejan llevar por la curiosidad, no tienen fuerza de voluntad y actúan sin pensar en las consecuencias.

Esta tarea, que permitió reflexionar también sobre por qué las personas que ofician misa o que ocupan los altos cargos en las jerarquías religiosas son siempre hombres, sirvió para que el alumnado detectara una forma más de discriminación hacia la mujer y, en la mayoría de los casos, se manifestara en contra, defendiendo que si una mujer conoce la palabra de Dios y quiere extenderla entre los creyentes, debería poder hacerlo y ascender en la jerarquía eclesiástica.

\section{Tarea 3: Machismo en los cuentos infantiles}

La literatura infantil y juvenil, cumple un papel fundamental como material de aula en la escuela. El cuento tradicional se utiliza de forma habitual pero no siempre lo analizamos para extraer los verdaderos valores que dicho cuento refuerza en nuestro alumnado. A través del cuento tradicional se refuerzan estereotipos que se alejan de un trato igualitario entre hombres y mujeres: matrimonio como finalidad última de las mujeres, belleza como cualidad perenne en la protagonista, sumisión al varón, etc. Por otro lado, el hombre se presenta como valiente, decidido, emprendedor. (VVAA, 2007)

Proponemos a nuestro alumnado el visionado de algunos fragmentos de cuentos infantiles, como el de Blancanieves y los siete enanitos. Es totalmente revelador el episodio en el que la protagonista llega a la casa de los enanitos y, al ver tanto desorden y suciedad, comenta que allí no debe vivir ninguna mujer, sino hombres y, más tarde, les propone a dichos personajes que la dejen quedarse y, a cambio, ella cocinará para ellos y tendrá la casa limpia.

Después de analizar algunos cuentos más (Cenicienta, donde se hace evidente que ella y sus hermanastras sólo buscan casarse con el príncipe, o La Bella durmiente, salvada por el valiente príncipe que supera innumerables obstáculos), proponemos a nuestro alumnado la siguiente tarea: escribe un cuento infantil desde una perspectiva de género, es decir, evitando todos estos estereotipos sexistas que hemos detectado en los cuentos infantiles tradicionales. (Como muestra, leímos el cuento El príncipe Ceniciento, de Colle, 1998).

He de decir que, de todas las tareas realizadas, esta fue una de las que más gustó, al alumnado. Surgieron cuentos muy interesantes, donde la mujer ya no aspiraba a casarse con el príncipe, sino que quería ser independiente, viajar, lograr un buen trabajo, etc. Era una mujer valiente, decidida que, en muchas ocasiones, huía de aparecer siempre bella. Además, la mayoría de los cuentos hacían un guiño a cuentos tradicionales existentes, negando todas aquellas situaciones que el alumnado había entendido como machistas (como en el caso de Cenicienta, donde en el nuevo cuento ella pierde el zapato porque le hacía daño y se lo quita y, además, huye de la vida palaciega que le ofrece el príncipe porque prefiere montar una escuela de paracaidismo).

\section{Tarea 4: Machismo en la educación y el acceso a profesiones}

Ya en el siglo XVIII comienzan las polémicas sobre el tipo de educación que debían recibir niños y niñas. Se defendía que las niñas no debían recibir una instrucción profunda porque ello las podría distraer de su función principal que no era otra que la de ser esposas y madres (Subirats, 1994). Con el tiempo, se hace necesario que las niñas reciban alguna formación que se hace imprescindible para que puedan trabajar. Surgen las escuelas para niñas, separadas de las escuelas para niños. En ambas se impartían enseñanzas totalmente distintas: las niñas aprendían, sobre todo, a rezar y coser, quedando la lectura, escritura y operaciones matemáticas en un segundo plano. A finales del XIX son muy pocas las mujeres que acceden a estudios superiores.

Aunque en varios países europeos se va introduciendo la escuela mixta (que entiende que la educación que han de recibir hombres y mujeres debe ser la misma), en España habrá que esperar a mediados del siglo XX para que se inauguren algunas de estas escuelas, práctica que quedó interrumpida durante la Guerra Civil (se impondría definitivamente en 1970). Con el franquismo, la mujer vuelve a estar relegada al ámbito doméstico, donde no necesita recibir una educación e instrucción igual que la del hombre. 
En 1970 se implanta la escuela mixta pero el debate de la coeducación no surge entonces, ya que primaban otras preocupaciones: diferencias de clases, falta de equipamientos, críticas a los contenidos impartidos por la escuela tradicional, etc. Se asume que no hay desigualdad en la educación que reciben niños y niñas porque estudian en el mismo sitio, con los mismos maestros y profesores. Nada más alejado de la realidad.

Hay estudios que demuestran que, todavía hoy, en los libros de texto que se usan en las aulas, sigue habiendo contenidos que refuerzan los roles tradicionales de la mujer: aparece como ama de casa, cuidando de niños pequeños o desempeñando las consabidas "profesiones de mujeres": enfermeras, maestras. Todavía hoy hay profesiones a las que accede un porcentaje muy bajo de mujeres, porque se consideran profesiones de hombres y viceversa (profesiones técnicas o relacionadas con las ciencias cuyo desempeño no depende de cuestiones biológicas, esto es, más o menos fuerza física, por ejemplo). Llegados a este punto, habría que estudiar el currículum oculto, es decir "las pautas de carácter no formal y sobre todo ideológico que se transmiten en la práctica escolar" (Subirats, 1994) que condicionan las aspiraciones profesionales del alumnado.

Otro dato a tener en cuenta es que en aquellas profesiones ejercidas de forma paritaria por hombres o mujeres, se detecta que los puestos más altos, de mayor responsabilidad, suelen estar ocupados por hombres. Parece ser que una de las causas radica en el hecho de que la mujer, por tener que encargarse en su tiempo libre de las tareas relacionadas con el hogar y la familia, no tiene tiempo para seguir formándose o para dedicar al trabajo un tiempo extra que le permitiera ascender, mientras que el hombre, generalmente, sí lo tiene.

Llegados a este punto (podríamos aportar innumerables datos que demuestran la existencia de desigualdad en el acceso a profesiones y sus causas; mujeres brillantes que han vivido a la sombra de sus maridos, etc. pero que, por cuestiones de espacio, no aportaremos aquí) y después de reflexionar sobre esta información, pedimos a nuestro alumnado que realice la siguiente tarea: lee el texto que se aporta (fragmento de la obra de Ramos Pérez, 2007) que recoge extractos de la teoría de la asignatura para mujeres "Economía doméstica para bachillerato y magisterio", de 1958, donde se divulga que la mujer debe desvivirse por agradar a su marido) y expresa tu opinión al respecto, poniéndote siempre en el lugar de la mujer a la que se dirige.

Sin duda, este texto fue el que generó mayor debate y discrepancias entre el alumnado. Eran muchos los alumnos que defendían algunas de las indicaciones que se dan en el texto, como que la mujer debía tener la casa caldeada en invierno, limpia y la comida preparada cuando su marido llegara del trabajo. Tanto alumnos como alumnas, en un alto porcentaje, defienden que si la mujer no trabaja fuera, debe realizar todas las tareas del hogar y que, incluso trabajando fuera, también (aunque, en este caso, algunos alumnos/as proponían que el marido podría "ayudarla" en algunas de ellas). Como vemos, un dato más que refleja que siguen existiendo situaciones de desigualdad en el ámbito doméstico, muchas de ellas alimentadas por el comportamiento de las propias mujeres que no intentan introducir cambio alguno. También es cierto que dichas situaciones se ven con más frecuencia en contextos rurales frente a urbanos y que dependen en gran medida de cuestiones culturales.

También aquí surgió una reflexión a propósito del ascenso de la mujer en el terreno profesional. Analizamos nuestro Centro y comprobamos que tanto el Director como el Jefe de Estudios eran hombres, situación que se repetía en Centros de pueblos cercanos conocidos por el alumnado, así como en los bancos y empresas de la zona, donde la dirección la ocupaba, normalmente, un hombre.

\section{6.- EVALUACIÓN}

Siempre que se lleva a la práctica una tarea encaminada a lograr unos objetivos, debemos evaluar no sólo si los objetivos se han logrado, sino si la tarea planteada, las estrategias, metodología, materiales, etc. han sido los adecuados. Por este motivo, distinguiremos dos tipos de evaluación:

a) Evaluación del alumnado: antes de comenzar a trabajar con este tipo de tareas, se le pasó una encuesta al alumnado con la finalidad de detectar actitudes machistas en su día a día. Se pudo comprobar que los chicos no realizaban tareas en el hogar, por ejemplo, mientras que las chicas sí 
“ayudaban” a sus madres en dichos quehaceres; no conocían el nombre de mujeres científicas, deportistas o, incluso, políticas. La encuesta, además, mostraba que la mayoría, tanto chicos como chicas, entendían que la mujer no debía trabajar fuera porque tenía que cuidar de los hijos. En última instancia, debía esperar a que éstos fueran mayores. Desde el principio quedó patente que los comportamientos que los jóvenes ven en sus casas son los que ellos mismos reproducen. Así, si un chico nunca ve cocinar o limpiar a su padre, él, por regla general, tampoco llevará a cabo estas tareas. Las madres también tienen mucho que ver, porque ellas deben tratar por igual a niños y a niñas en casa, y enseñar a ambos a realizar las mismas tareas del hogar (los propios alumnos reconocían que sus madres nunca les habían pedido que pusieran la lavadora, cocinaran, plancharan, etc. mientras que las alumnas sí han sido iniciadas en dichas tareas desde pequeñas. Esto demuestra que, en muchos casos son, precisamente, las mujeres las que reproducen las desigualdades en el ámbito doméstico).

A finales de curso, se volvió a pasar la misma encuesta y pudo comprobarse, gratamente, que muchos de los alumnos sí podían dar el nombre de mujeres importantes en la Historia (científicas, matemáticas, escritoras, etc.), políticas, deportistas; y, además, muchos de ellos habían empezado a encargarse de realizar algunas de las tareas de casa, actuaciones tan simples como hacerse la cama, poner o recoger la mesa o recoger la ropa seca, algo impensable unos meses atrás. Es preciso hacer hincapié en un detalle que cobra gran importancia: el alumnado dejó de utilizar la expresión "ayudar a mi madre a hacer las cosas de casa" y usaba otras como "hacer tareas en casa". Este gesto es revelador porque demuestra que el alumnado entendió, no con poco esfuerzo, que las tareas de casa no eran algo propio de la madre y que, por tanto, no se le "ayudaba" cuando se hacía alguna de ellas.

Con esta encuesta, y con los textos orales y escritos realizados, evaluamos el grado de consecución de los objetivos planteados al principio, pudiendo comprobar que se lograron en un porcentaje muy alto. (Además, se trabajó constantemente la expresión y comprensión oral y escrita, haciendo continuas correcciones en lo referente a ortografía, coherencia y cohesión, propiedad en el uso de vocabulario, etc. mejorando así la competencia lingüística del alumnado).

b) Evaluación de la práctica docente y metodología: si partimos del hecho de que los objetivos marcados al inicio de la experiencia se han logrado en un alto porcentaje, todo hace pensar que se han seguido los métodos adecuados. El alumnado responde bien cuando se alternan momentos de teoría y práctica, es decir, trabaja de forma positiva cuando el tiempo dedicado a recibir información de forma unidireccional por parte del profesor no es excesivamente largo con respecto al tiempo que se emplea para interiorizar dicha información, bien sea a través de la investigación autónoma haciendo uso de las TIC, de la creación de textos donde se plasmen las ideas y opiniones (de forma escrita o en debates en grupo). Por tanto, esta metodología, dinámica y centrada en el aprendizaje autónomo del alumno, fue, sin duda, la más acertada.

Otro acierto que se puede destacar es la elección del enfoque. Queríamos lograr que el alumnado asumiera la existencia de comportamientos machista a su alrededor. Es novedoso y motivador, por ejemplo, pedir al alumnado que vea la televisión y que preste atención a los anuncios, quedándose con aquellos en los que podrían aparecer los estereotipos estudiados en clase. De la misma manera, le resultó entretenido ver en televisión algunos cuentos tradicionales llevados al cine, intentando detectar aquellas situaciones, expresiones y comportamientos que podrían considerarse machistas. No podemos lograr que el alumnado interiorice una información, aunque la consideremos un axioma, si para ello usamos la técnica de dictar apuntes que contengan dicha información, sin someterlos a crítica, sin probarlos o relacionarlos con casos reales.

Además de las tareas presentadas aquí, han de citarse otras que se realizaron y que, igualmente, merecen una valoración positiva: visionado y comentario de la película Un burka por amor, realización de murales que mostraran las diferencias entre lo que hace una mujer a lo largo del día y lo que hace un hombre (se quería hacer hincapié en que el hombre, normalmente, trabaja fuera de casa y no realiza tareas del hogar mientras que la mujer, aunque trabaje fuera, suele encargarse también de los quehaceres domésticos), análisis de canciones de actualidad donde se habla de malos tratos hacia la mujer o donde se la discrimina porque aparece como "mujer objeto" (para este último 
caso, analizamos canciones de Reggaeton), encuestas realizadas por nuestro alumnado, dramatizaciones, etc.

\section{7.- REPERCUSIÓN PEDAGÓGICA}

Esta experiencia que se ha presentado viene a ser una más de entre otras muchas ya existentes, que se enmarca en la lucha por lograr que las generaciones futuras erradiquen los comportamientos machistas y discriminatorios hacia la mujer. Es inadmisible que, día a día, vayan sumándose nombres de mujeres que mueren a manos de sus parejas porque éstos se consideran sus dueños, o porque se creen mejores o porque entienden que "su mujer" debe hacer lo que ellos le ordenen. Desde el hogar y desde la escuela debemos fomentar comportamientos pacíficos, tolerantes y paritarios entre unos y otros y, particularmente, entre personas de diferente sexo. Nuestros jóvenes han de entender que el hecho de ser hombre o mujer no da o quita derechos, porque todos tenemos los mismos derechos y los mismos deberes y, entre estos últimos, está el derecho a ser feliz, a vivir de forma digna, a no ser vejado, acosado, humillado, discriminado, a recibir un trato correcto, respetuoso, de los demás, independientemente del sexo que se tenga.

Las tareas que aquí se han mostrado y otras muchas que, por cuestiones de espacio, no se han podido presentar, buscan ser, únicamente, una herramienta más que puede emplearse en esta lucha por conseguir la igualdad de oportunidades entre hombres y mujeres. Los docentes que impartan materias de ciencias pueden hablar de mujeres importantes en esta rama; los de Historia, Lengua y Literatura, Filosofía, Música, Educación Física, etc., encontrarán innumerables ejemplos de mujeres que sobresalen en dichas materias también. Pero nuestra labor no queda ahí. Tenemos que esforzarnos para que en el aula, el trato que se da a chicos y a chicas sea el mismo (y da igual si estamos en el taller de tecnología, en el gimnasio o en cualquier otro espacio): debemos enseñar y exigir lo mismo tanto a chicos como a chicas (con las salvedades que existan y que se relacionan con cuestiones biológicas). En este sentido, podemos reconocer, con optimismo, que los libros de texto, cada vez más, emplean un enfoque coeducativo, los medios de comunicación también revelan ciertos visos de trabajar en esta misma línea, buscando eliminar los consabidos estereotipos relacionados con la mujer.

Todos estos datos son muy esperanzadores para el docente en esta lucha por conseguir entre el alumnado comportamientos basados en la igualdad entre hombres y mujeres, ya que dichos comportamientos no pueden lograrse únicamente trabajando desde la escuela o el instituto, sino que han de tener su reflejo en la sociedad, en los contextos en los que se mueven nuestros jóvenes.

\section{8.- CONCLUSIONES}

A pesar de que el machismo, la discriminación hacia la mujer, ha sido un hecho desde tiempo inmemoriales, es en la actualidad cuando se está tomando conciencia de ello y se están marcando las pautas para corregirlo. La escuela, el instituto, debe ser uno de los escenarios en los que, de forma obligatoria, se promuevan medidas y actuaciones para corregir y erradicar dicha discriminación hacia la mujer. Por este motivo, este trabajo es muy útil ya que viene a enriquecer el corpus literario existente en lo que se refiere a medidas y material didáctico orientado a dicho fin.

A pesar de que es abundante la literatura que analiza, reflexiona y clarifica el problema latente de las desigualdades entre los sexos, no lo es tanto aquélla que ofrece mecanismos concretos para trabajar en el aula de forma práctica, real y funcional, haciendo que el alumnado profundice en la realidad de su propio entorno, reflexionando y detectando comportamientos machistas en su propio día a día. Este trabajo, la experiencia que se presenta, sí ofrece al docente mecanismos, material, estrategias e ideas para abordar dicho tema, haciendo uso de una metodología que implica al alumnado en su propio aprendizaje, captando su interés y logrando así que este trabajo se convierta en herramienta útil para el docente que aborde en el aula esta problemática social.

\section{0.- REFERENCIAS BIBLIOGRÁFICAS}

Aznar, P. y Cánovas P. (Eds.) (2008). Educación, género y políticas de igualdad. Universitat de València, Valencia. 
Claramunt Vallespí, T. el al., (2007). Cambios Sociales y de Género. Guía didáctica. Junta de Andalucía (Ed.). Disponible en www.educacionenvalores.org/spip.php?article2171.

Colle, B. (1998). El príncipe Ceniciento. Barcelona: Destino.

Consejería de Educación (Ed.) (2007). Estudio sobre la incidencia del I Plan de Igualdad en Andalucía. Sevilla. En www.oei.es/genero/documentos/esp/I_Plan_de_igualdad_Andalucia.pdf.

Davies, B. (1989). Sapos y culebras y cuentos feministas. Madri: Cátedra.

Decreto 231/2007 de 31 de julio, por el que se establece la ordenación y las enseñanzas correspondientes a la Educación Secundaria Obligatoria en Andalucía (nº 156, de 8 de agosto de 2007).

Diccionario de la Lengua Castellana, (21 ${ }^{\mathrm{a}}$ ed.). Madrid: Espasa Calpe. Disponible en http://www.rae.es.

Escudero Carretero, M., Pulido Villegas, M. y Venegas Franco, F. (2003). Un mundo por compartir. Guía didáctica de Educación para el desarrollo desde una perspectiva de género. Granada: Aspa. Disponible en www.educacionenvalores.org/IMG/pdf/Guia_Profesorado.pdf.

Estaire, S. (2004). La programación de unidades didácticas a través de las tareas. Revista RedELE, 1 [en línea]. Disponible en www.mec.es/redele/revista1/pfds1/estaire.pdf.

Harris, M. (1983) Caníbales y reyes. Los orígenes de la cultura. Barcelona: Argos Vergara.

Ley Orgánica 2/2006 (LOE), de 3 de mayo, de Educación (BOE nº 106, de 4 de mayo). Madrid: Ministerio de Educación.

Lobato, E. (2010). Construyendo el género. La escuela como agente educador. En http://web.educastur.princast.es/proyectos/coeduca/?page_id=5

Moreno, J. y Sánchez-Oro, M. (2000). Un estudio cualitativo de la minoría gitana. Vigencia de los componentes de la estructura social, En http://sociologiaext.wordpress.com/2007/05/16/un-estudio-cualitativo-de-laminoria-gitana-vigencia-de-los-componentes-de-la-estructura-social/.

Pujolás, P. (2001). Atención a la diversidad y aprendizaje colaborativo. Archidona: Aljibe.

Ramos Pérez, R. (2007). La igualdad de oportunidades entre hombres y mujeres. Valencia: Germania.

Real Decreto 1631/2006 de 29 de diciembre, por el que se establecen las enseñanzas mínimas correspondientes a la Educación Secundaria Obligatoria. (BOE $n^{\circ}$ 5, de 5 de enero de 2007).

Red2Red Consultores (2007). Guía de coeducación. Documento de síntesis sobre la educación para la igualdad de oportunidades entre hombres y mujeres. Madrid: Instituto de la Mujer. Ministerio de Trabajo y asuntos sociales. Disponible en http://redes.cepcordoba.org/mod/resource/view.php?id=659.

Suárez Villegas, J. C. (2007). Estereotipos de la mujer en la comunicación. En www.nodo50.org/mujeresred/IMG/pdf/estereotipos.pdf.

Subirats Martori, M. (1993). El trabajo doméstico nueva frontera para la igualdad. En L. Garrido Medina y E. Gil Calvo (eds). Estrategias familiares (pp. 299-315). Madrid: Alianza.

Subirats Martori, M. (1994). Conquistar la igualdad. La coeducación hoy. Revista Iberoamericana de Educación, 6, Septiembre-Diciembre, [en línea] Disponible en www.rieoei.org/oeivirt/rie06a02.htm

VVAA (2007). Analizamos el sexismo en la literatura infantil. En http://web.educastur.princast.es/proyectos/coeduca/wp-content/uploads/2007/04/libros.pdf

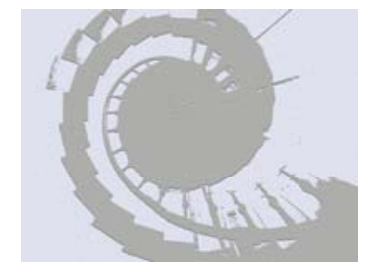

